\title{
Effect of norepinephrine challenge on cardiovascular determinants assessed using a mathematical model in septic shock: a physiological study
}

\author{
Huaiwu He ${ }^{1}$, Siyi Yuan ${ }^{1}$, Yun Long ${ }^{1}$, Dawei Liu ${ }^{1}$, Xiang Zhou ${ }^{1}$, Can Ince ${ }^{2}$ \\ ${ }^{1}$ Department of Critical Care Medicine, State Key Laboratory of Complex Severe and Rare Diseases, Peking Union Medical College Hospital, \\ Peking Union Medical College, Chinese Academy of Medical Science, Beijing, China; ${ }^{2}$ Department of Intensive Care, Erasmus MC University \\ Hospital, Rotterdam, The Netherlands \\ Contributions: (I) Conception and design: H He, X Zhou, Y Long, D Liu; (II) Administrative support: X Zhou, Y Long, D Liu; (III) Provision of \\ study materials or patients: H He, S Yuan; (IV) Collection and assembly of data: H He, S Yuan; (V) Data analysis and interpretation: H He, X Zhou, \\ Y Long, D Liu, C Ince; (VI) Manuscript writing: All authors; (VII) Final approval of manuscript: All authors. \\ Correspondence to: Yun Long, MD; Dawei Liu, MD. Department of Critical Care Medicine, Peking Union Medical College Hospital, Chinese \\ Academy of Medical Science, 1 Shuaifuyuan, Dongcheng District, Beijing, China. Email: iculong_yun@163.com; tjmuhhw@163.com.
}

Background: The present study investigated the cardiovascular determinants of cardiac output (CO), mean systemic filling pressure analogue (Pmsa) derived by Geoffrey Parkin, efficiency of heart (Eh) and related parameters to a norepinephrine (NE) challenge [an increase of $10 \mathrm{mmHg}$ mean arterial pressure (MAP) by $\mathrm{NE}$ ] in septic shock patients using of a mathematical model.

Methods: Twenty-seven septic shock patients with pulse index continuous cardiac output (PiCCO) monitoring were enrolled. These patients required NE to maintain an individualized MAP for organ perfusion after early fluid resuscitation based on their clinical condition. NE was decreased to obtain a decrease of $10 \mathrm{mmHg}$ from base $\mathrm{MAP}\left(\mathrm{MAP}_{-10 \mathrm{mmHg}}\right)$, and the NE doses were adjusted to return MAP to baseline $\left(\mathrm{MAP}_{\text {base }}\right)$ and produce an increase of $10 \mathrm{mmHg}$ from $\mathrm{MAP}_{\text {base }}\left(\mathrm{MAP}_{+10 \mathrm{mmHg}}\right)$. Two NE challenge episodes were analyzed for each patient: from $\mathrm{MAP}_{-10 \mathrm{mmHg}}$ to $\mathrm{MAP}_{\text {base }}$ and from $\mathrm{MAP}_{\text {base }}$ to $\mathrm{MAP}_{+10 \mathrm{mmHg}}$. The Pmsa, pressure gradient for venous return $\left(\mathrm{PG}_{\mathrm{vr}}\right)$, and Eh (PGvr relative to Pmsa) were estimated using a mathematical model for the three MAP levels $\left(\mathrm{MAP}_{-10 \mathrm{mmHg}}, \mathrm{MAP}_{\text {base }}\right.$ and $\left.\mathrm{MAP}_{+10 \mathrm{mmHg}}\right)$.

Results: A total of 54 episodes of NE challenges were obtained in 27 patients. Significant and consistent increases were observed in the central venous pressure (CVP), Pmsa, and PGvr in response during the NE titration. $\Delta \mathrm{CO}$ negatively and significantly correlated with $\Delta \mathrm{CVP}(\mathrm{r}=-0.722, \mathrm{P}<0.0001), \Delta \mathrm{Pmsa}(\mathrm{r}=-0.549$, $\mathrm{P}<0.0001), \Delta$ Resistance of venous return (Rvr) $(\mathrm{r}=-0.597, \mathrm{P}<0.0001)$, and $\Delta$ Resistance of systemic vascular beds (Rsys) ( $\mathrm{r}=-0.597, \mathrm{P}<0.0001)$. Episodes of decreasing $\mathrm{CO} /$ Eh were associated with a higher $\Delta \mathrm{CVP}$ than the CO/Eh-increasing episodes. The area under the curve (AUC) of $\triangle \mathrm{CVP}$ to predict decreased CO by the incremental NE was 0.86 , and the AUC of $\triangle \mathrm{CVP}$ to predict decreased Eh was 0.94 . A cutoff of $\triangle \mathrm{CVP}$ $>1.5 \mathrm{mmHg}$ for detecting decreased CO resulted in a sensitivity of $75 \%$ and a specificity of $94.1 \%$. A cutoff of $\triangle \mathrm{CVP}>1.5 \mathrm{mmHg}$ for detecting decreased Eh resulted in a sensitivity of $64.3 \%$ and a specificity of $100 \%$. Conclusions: There were a highly divergent response in Eh and CO to afterload challenge episodes of an NE-induced $10 \mathrm{mmHg}$ increase in MAP. An increase in CVP may be an early alarm to identify the reduction in CO/Eh during an NE-induced increase of MAP.

Keywords: Mean systemic pressure; norepinephrine (NE); septic shock; cardiac output; cardiac efficiency

Submitted Sep 30, 2020. Accepted for publication Jan 12, 2021.

doi: 10.21037/atm-20-6686

View this article at: http://dx.doi.org/10.21037/atm-20-6686 


\section{Introduction}

Norepinephrine (NE) is recommended as the first choice to maintain mean arterial pressure (MAP) during the resuscitation from septic shock (1). The primary aim of an $\mathrm{NE}$ infusion is to increase and maintain MAP. However, other effects of NE on hemodynamics, such as effects on the mean systemic filling pressure (Pmsf), venous return, systemic circulation, and cardiac function, must be considered in clinical practice (2). Recent attention focused on the venous return [equal to cardiac output (CO)] response to incremental NE infusions in critically ill patients. Notably, the CO response to $\mathrm{NE}$ is variable, as determined by the interaction of the venous return curve and cardiac function curve. Researchers demonstrated that the effect of $\mathrm{NE}$ on venous return varies in critically ill patients $(3,4)$. Maas et al. found the NE-induced change in $\mathrm{CO}$ was determined by the balance of volume recruitment (increase in mean systemic filling pressure as assessed using the inspiratory-hold method), change in resistance for venous return, and baseline heart function (3). Persichini et al. found that the decrease of NE was responsible for a decrease in venous return due to the decrease in mean systemic pressure as measured using the inspiratory/ expiratory-hold method (4). However, the inspiratory/ expiratory-hold method requires deep sedation, and it is a complex procedure. It is inconvenient for a physician to use the inspiratory/expiratory-hold method to measure Pmsf and related parameters at the bedside. Therefore, a simple method to measure Pmsf would help the interpretation of the hemodynamic effect of NE in septic shock patients. According to an electrical analog simplification of Guyton circulatory physiology, Parkin proposed a mathematical model analog of mean systemic pressure (Pmsa) that may be calculated from directly measured right atrial pressure (RAP), MAP and CO (5). Werner-Moller et al. recently compared the agreement of Pmsf between various indirect measured methods (inspiratory-hold method, instantaneous beat-to-beat venous return method and mathematical model analog method) and the direct method (measured at zero flow using right atrial balloon occlusion) at various volume statuses in an animal study (6). The authors found that the mathematical model analog method had better agreement with the direct measured method of Pmsf than the other indirect methods (6). The same team further found that an increase in NE increased extracorporeal membrane oxygenation (ECMO) flow via the combined effect of recruit volume, increased Pmsf, as measured using a stop flow maneuver, and increased venous return and pump afterload in an animal model of ventricular fibrillation with venoarterial ECMO (VA-ECMO) therapy (7). Therefore, the use of this model would include the Pmsa and Pmsaderived variables in the interpretation of the effects of $\mathrm{NE}$ on $\mathrm{CO}$ at bedside. To the beset of our knowledge, no published study quantified the $\mathrm{CO}$ response to increased NE using Pmsa and Pmsa-derived variables in clinical practice.

The present study investigated the CO response to an $\mathrm{NE}$ challenge (titrated to achieve an increase of $10 \mathrm{mmHg}$ MAP) in septic shock patients. The quantitative relationship of hemodynamic variables, including a mathematical model to calculate Pmsa and related parameters, to the response of $\mathrm{CO}$ to the NE challenge was investigated.

Some of the patients in the present study were included in a previously reported study on the effects of $\mathrm{NE}$ on the peripheral perfusion index (8). We present the following article in accordance with the STARD reporting checklist (available at http://dx.doi.org/10.21037/atm-20-6686).

\section{Methods}

\section{Patients}

The investigation was performed according to the principles outlined in the Declaration of Helsinki (as revised in 2013). The Institutional Research and Ethics Committee of the Peking Union Medical College Hospital approved this study for human subjects (No. ZS-910, approved at 2015). Written informed consent was obtained from all patients or next of kin before the data were included in the study.

All adult patients with septic shock who were prospectively admitted to the Department of Critical Care Medicine of Peking Union Medical College Hospital and who required pulse index continuous cardiac output (PiCCO) plus CO hemodynamic monitoring for resuscitation were eligible for the study when the research team was available. The attending intensivists based decisions on PiCCO catheter placement on the severity of the patient's condition after early hemodynamic support. The PiCCO catheter was placed in the femoral artery using a standard operating procedure. Septic shock was defined as severe sepsis with sepsis-induced hypotension that persisted despite adequate fluid resuscitation and required the administration of vasopressors (9). All of the included patient received NE to maintain the individualized MAP levels, which were set based on the patient's usual levels and 
organ perfusion via clinical decision.

\section{Measurements}

Information collected at enrollment included demographic characteristics, such as age, sex, Acute Physiology and Chronic Health Evaluation II score (APCHE II) (10), and primary site and type of infection. The flow chart of NE titration and hemodynamic data collection was presented in the previous study (8).

The NE challenge was defined as an elevation of $10 \mathrm{mmHg}$ MAP that occurred from the NE increase. NE initially induced a $10-\mathrm{mmHg}$ reduction in baseline MAP $\left(\mathrm{MAP}_{\text {base }}\right)$, which we called the $\mathrm{MAP}_{-10 \mathrm{mmHg}}$ level. Second, $\mathrm{NE}$ was increased to restore the $\mathrm{MAP}_{\text {base }}$ level. Last, NE was increased further to obtain a $10-\mathrm{mmHg}$ increase from $\mathrm{MAP}_{\text {base, }}$ which was the $\mathrm{MAP}_{+10 \mathrm{mmHg}}$ level. The two NE challenge tests were captured during the NE titration: the $1^{\text {st }}$ test was from $\mathrm{MAP}_{-10 \mathrm{mmHg}}$ to $\mathrm{MAP}_{\text {base }}$ levels, and the $2^{\text {nd }}$ test was from $\mathrm{MAP}_{\text {base }}$ to $\mathrm{MAP}_{+10 \mathrm{mmHg}}$ levels. We allowed 10 minutes for hemodynamic adaptation at the three MAP levels. The heart rate (HR), central venous pressure (CVP), systolic/diastolic blood pressure (SBP/DBP), MAP, continuous cardiac output (CCO) and related parameters were continuously and simultaneously recorded. When a significant increase of CVP $(>3 \mathrm{mmHg})$ and/or a decrease of $\mathrm{CO}(>2 \mathrm{~L} / \mathrm{min})$ was observed, the balancing time of hemodynamics to the NE increase was reduced to decrease hemodynamic disturbances in response to the increased NE.

\section{Determination of Pmsa and related variables}

(I) Pmsa $=(\mathrm{a} \times \mathrm{CVP})+(\mathrm{b} \times \mathrm{MAP})+(\mathrm{c} \times \mathrm{CO})$, where a and $\mathrm{b}$ are dimensionless constants $(\mathrm{a}+\mathrm{b}=1$; typically $\mathrm{a}$ $=0.96$ and $b=0.04$ ), and $c$ is calculated by the patient's the height and weight. The mathematical model of the systemic circulation was composed of compliant arterial and venous compartments and resistances to blood flow (5). MPA and CO were measured by the PiCCO machine.

(II) Resistance of systemic vascular beds $\left(\mathrm{R}_{\mathrm{SYS}}\right)=(\mathrm{MAP}$ - CVP)/CO. Total vascular systemic resistance was calculated as the ratio of the pressure difference between MAP and CVP to the CO.

(III) Resistance of venous return $(\mathrm{Rvr})=(\mathrm{Pmsa}-\mathrm{CVP}) /$ CO. Pmsa was the average pressure in the systemic circulation, and Rvr was the resistance encountered to the heart (11). This formula is used to describe venous return during transient states of imbalances (12).

(IV) Pressure gradient for venous return $\left(\mathrm{PG}_{\mathrm{VR}}\right)=$ Pmsa CVP. The PGvr was defined as the pressure difference between Pmsa and CVP.

(V) Efficiency of the heart $\left(\mathrm{E}_{\mathrm{h}}\right)=\left(\mathrm{P}_{\mathrm{msa}}-\mathrm{CVP}\right) / \mathrm{P}_{\mathrm{msa}}(5)$. This equation was proposed by Parkin WG for the measurement of heart performance. During the cardiac stop ejection, CVP is equal to the Pmsa, and Eh approaches zero.

\section{Statistical analysis}

Descriptive analyses were performed. All data are expressed as medians $(25-75 \%$ percentile) or means \pm standard deviation. Comparisons of related parameters based on the different MAP levels were performed using a general linear model repeated measures (GLMRM) model $(13,14)$. This model is an extension of the classic ANOVA and allows assessments of fixed effects (MAP levels) and random effects (patient). The GLMRM model takes into account the correlation between multiple measurements of one patient. Therefore, the estimated marginal means were adjusted for the covariates, and the trends of related hemodynamic parameters corresponding to the different MAP levels are shown. Repeated measurements were analyzed using analysis of variance or analysis of variance on ranks. Paired data were compared using the $t$-test or the Wilcoxon signedrank test. Comparisons of two continuous variables were performed using a linear regression. Discrimination of values for the prediction of $\mathrm{CO} / \mathrm{Eh}$ directional changes (increase or decrease) were assessed using receiver operating characteristic (ROC) analysis. All comparisons were two-tailed, and $\mathrm{P}<0.05$ was required to exclude the null hypothesis. The statistical analyses were performed using the software package SPSS 21.0 (SPSS Inc., Chicago, IL, USA).

\section{Results}

Twenty-seven septic shock patients were enrolled, and the age was 59 [41-73] years. The demographic and clinical characteristics of the study group are shown in Table 1 . There were no adverse effects associated with the NE challenges.

\section{Effects of NE on the hemodynamic variables}

The doses of the NE infusion were significantly increased from $0.32(0.09-0.89)$ to $0.37(0.22-1.08)$ and $0.49(0.26-$ 
Table 1 Characteristics of the patients at inclusion

\begin{tabular}{lc}
\hline Parameter & Value \\
\hline Number of patients & 27 \\
Age (years) & $59[41-73]$ \\
Sex (female/male) & $13 / 14$ \\
Medical history of hypertension & $14 / 27$ \\
APACHE Il score & $22[15-31]$ \\
$\mathrm{BMI}$ & $24[21-28]$ \\
$\mathrm{FiO}$ & $(\%)$ \\
$\mathrm{PEEP}$ & $45[40-50]$ \\
Tidal volume $(\mathrm{mL})$ & $5[5-10]$ \\
$\mathrm{GEDVI}$ & $420[385-470]$ \\
EVLWL & $687[632-811]$ \\
$\mathrm{NE}$ dose $(\mu \mathrm{g} / \mathrm{kg} / \mathrm{min})$ & $9.1[7.2-9.9]$ \\
\hline
\end{tabular}

Data are presented as median [25-75\% percentile]. APACHE II, Acute Physiology and Chronic Health Evaluation II; BMI, body mass index; NE, norepinephrine; PEEP positive end-expiratory pressure $\left(\mathrm{cmH}_{2} \mathrm{O}\right)$; GEDVI, global end-diastolic volume index $\left(\mathrm{mL} / \mathrm{m}^{2}\right)$; EVLWL, extravascular lung water index.
1.15) $\mu \mathrm{g} / \mathrm{kg} / \mathrm{min}$ for the different assigned MAP levels. The NE-induced variations in hemodynamic variables are listed in Table 2. Increasing the dose of NE was associated with consistent increases in SBP, DBP, MAP, CVP and $\mathrm{dP} / \mathrm{dtmax}$ (dPmax). A significant decrease in stroke volume variation (SVV) was observed during MAP titration. However, there were no significant or consistent changes in the trends for $\mathrm{CO}$ or HR. Figure 1 shows the variations in the estimated marginal means for CO, MAP CVP and HR in the 27 patients at the three MAP levels.

There was individual variability in the $\mathrm{CO}$ changes at different MAP levels produced by the increased NE. With the same directional change, a consistent decrease in $\mathrm{CO}$ in 8 patients and an increase in $\mathrm{CO}$ in 14 patients was observed during the stepwise incremental NE process. The $\mathrm{CO}$ change in direction was not inconsistent in 5 patients.

The increased NE infusion produced a consistent and significant increase in Pmsa, Rsys, Rvr and PGvr with a linear trend $(\mathrm{P}<0.0001)$. However, the change in Eh showed no significant linear change trend (Table 1). There was no significant difference in Eh between $\mathrm{MAP}_{-10 \mathrm{mmHg}}$ and $\mathrm{MAP}_{\text {base }}$ levels. Figure 2 shows the variation in estimated

Table 2 Effects of NE on the hemodynamic variables at different MAP levels in 27 patients

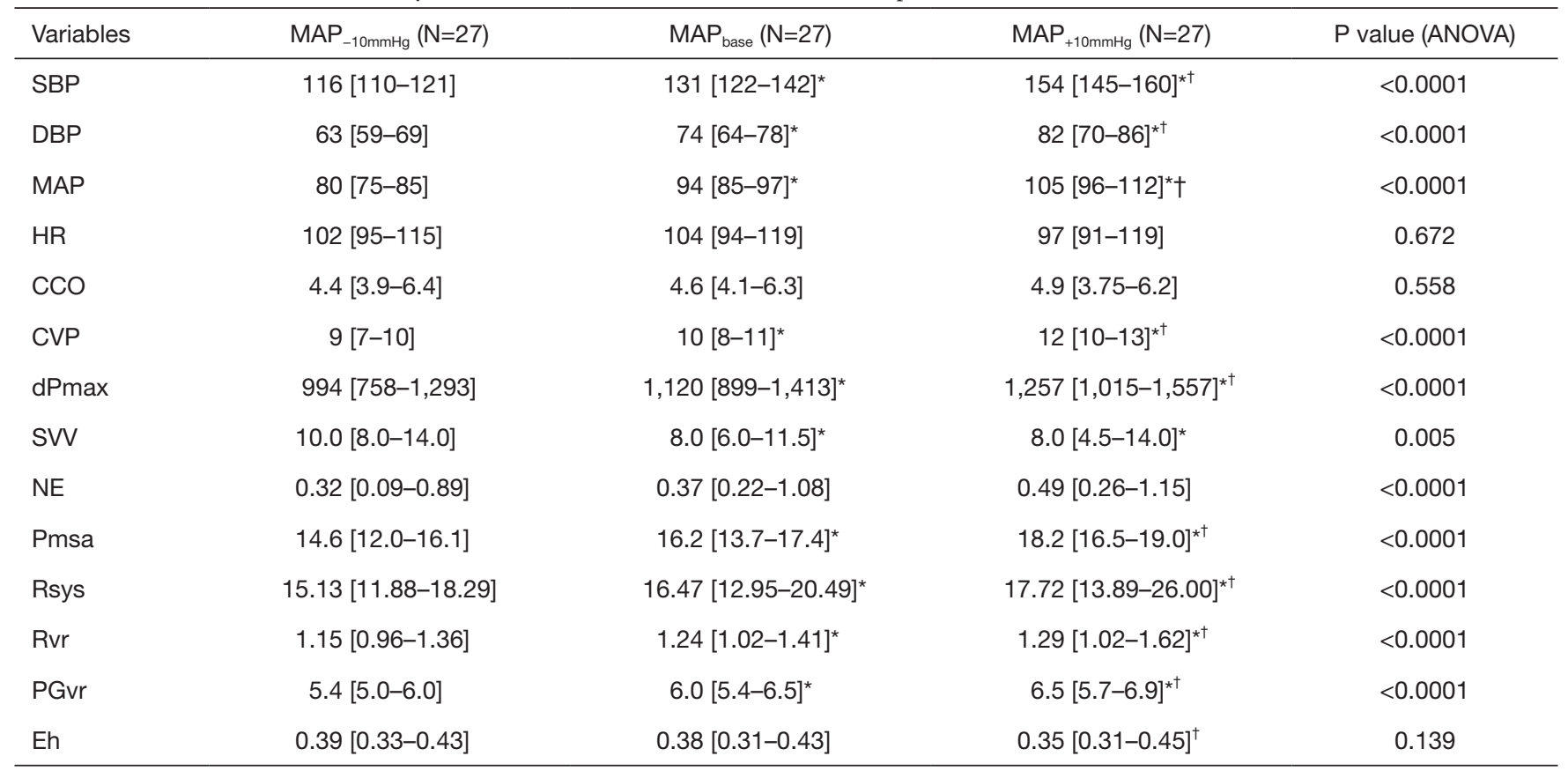

Data are presented as median [25-75\% percentile]. ${ }^{*}, \mathrm{P}<0.05$ vs. $\mathrm{MAP}_{-10 \mathrm{mmHg}} ;{ }^{\dagger}, \mathrm{P}<0.05$ vs. MAP base. MAP, mean arterial pressure (mmHg); $\mathrm{SBP}$, systolic arterial pressure $(\mathrm{mmHg})$; DBP, diastolic arterial pressure $(\mathrm{mmHg})$; HR, heart rate; CCO, continuous cardiac output $(\mathrm{L} / \mathrm{min})$; CVP, central venous pressure; dPmax, maximum rate of the increase in pressure; SVV, stroke volume variation (\%); NE, norepinephrine ( $\mu \mathrm{g} / \mathrm{kg} / \mathrm{min})$; Pmsa, systolic arterial pressure (mmHg); Rsys, resistance of systemic vasculature; Rvr, resistance of venous return; PGvr, pressure gradient for venous return; Eh, efficiency of heart. 

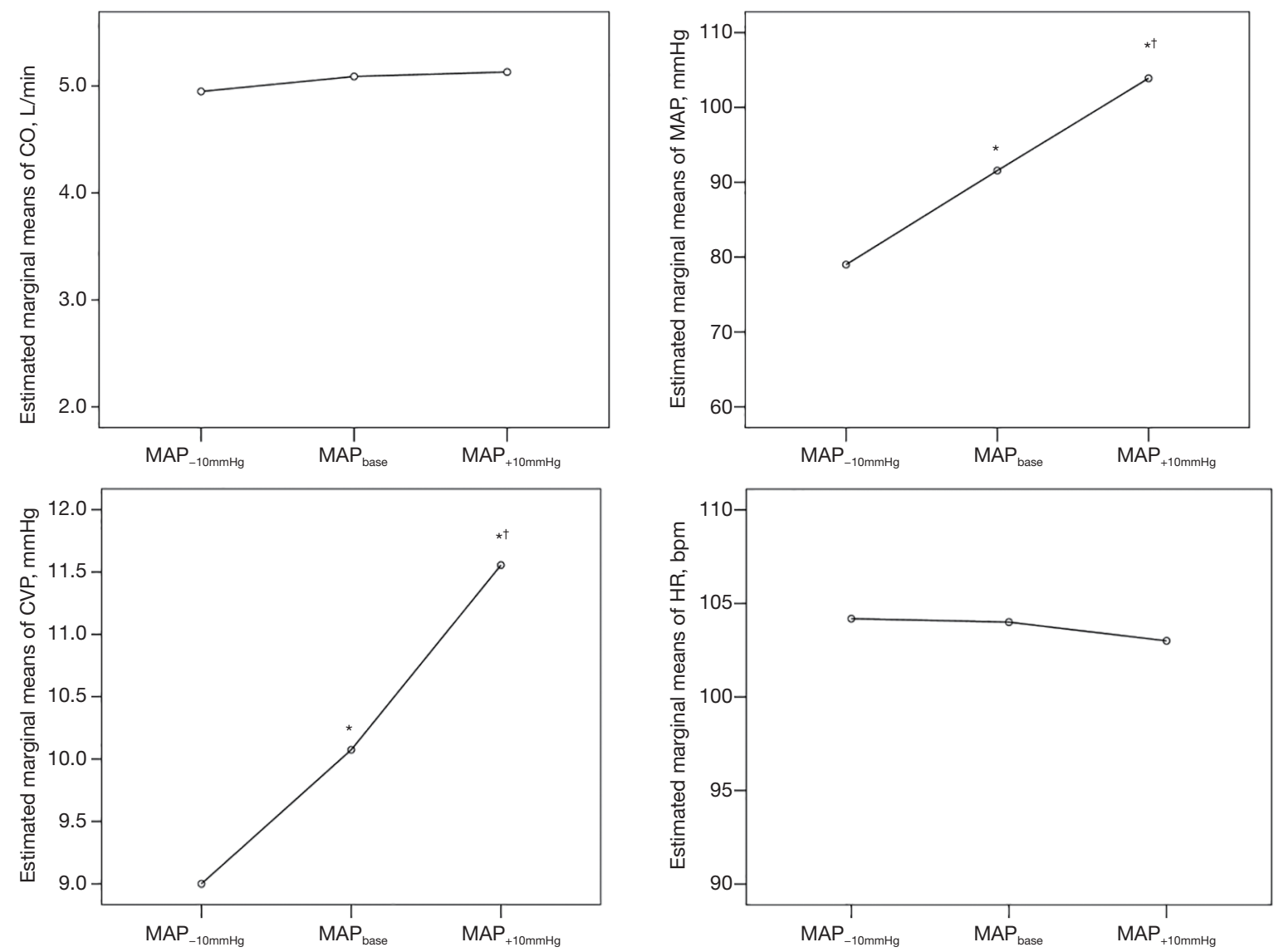

Figure 1 Estimated marginal means of CO, MAP, CVP and HR in 27 patients at three MAP levels. ${ }^{*}, \mathrm{P}<0.05 v s . \mathrm{MAP}_{-10 \mathrm{mmHg}}{ }^{\dagger}, \mathrm{P}<0.05$ vs. $\mathrm{MAP}_{\text {base }}$. MAP, mean arterial pressure; CO, cardiac output; CVP, central venous pressure; HR, heart rate.

marginal means for PGvr, Rsys, Rvr, and Eh at the three MAP levels.

\section{Correlation between changes in $\mathrm{CO}$ and changes in related parameters in the $54 \mathrm{NE}$ challenge episodes}

The $\Delta \mathrm{CO}$ positively and significantly correlated with $\triangle \mathrm{PGvr}$ $(\mathrm{r}=0.917, \mathrm{P}<0.0001), \Delta \mathrm{Eh}(\mathrm{r}=0.802, \mathrm{P}<0.0001)$ (Figure 3) and $\Delta \mathrm{HR}(\mathrm{r}=0.354, \mathrm{P}=0.009)$ (Figure 3$). \Delta \mathrm{CO}$ negatively and significantly correlated with $\triangle \mathrm{CVP}(\mathrm{r}=-0.722, \mathrm{P}<0.0001)$ (Figure 3), $\Delta \mathrm{Pmsa}(\mathrm{r}=-0.549, \mathrm{P}<0.0001)$ (Figure 3), $\Delta \mathrm{Rvr}$ $(\mathrm{r}=-0.597, \mathrm{P}<0.0001)$, and $\Delta$ Rsys $(\mathrm{r}=-0.597, \mathrm{P}<0.0001)$. However, there was no significant relationship between $\Delta \mathrm{CO}$ and $\Delta \mathrm{SVV}(\mathrm{r}=-0.284, \mathrm{P}=0.841)$ or $\triangle \mathrm{MAP}(\mathrm{r}=-0.099$, $\mathrm{P}=0.478)$.

\section{Prediction of $\mathrm{CO}$ and $\mathrm{Eb}$ responses to the $54 \mathrm{NE}$ challenges}

For the $\mathrm{CO}$ responses, the $54 \mathrm{NE}$ challenges were divided into CO-decreasing $(\Delta \mathrm{CO}<0, \mathrm{n}=20)$ and $\mathrm{CO}$-increasing $(\Delta \mathrm{CO}>0, \mathrm{n}=32$, including $30 \Delta \mathrm{CO}>0$ and $2 \Delta \mathrm{CO}=0$ ) episodes. For the Eh responses, the $54 \mathrm{NE}$ challenges were divided into Eh-amplifying and Eh-reducing episodes. The CO-decreasing group had a significantly higher $\triangle \mathrm{CVP}$ than the CO-increasing group [ $\triangle \mathrm{CVP}(\mathrm{mmHg})$ : CO-increasing $v$ s. CO-decreasing, $0.6+0.9$ vs. 2.4+1.3, respectively; $\mathrm{P}<0.0001$ ]. The NE challenges in the Eh-reducing episodes $(n=26, \Delta E h$ $<0)$ had significantly higher $\triangle \mathrm{CVP}$ than the Eh-amplifying episodes $(\mathrm{n}=28, \Delta \mathrm{Eh}>0)[\Delta \mathrm{CVP}(\mathrm{mmHg})$ : Eh-reducing vs. Eh-amplifying, $2.2+1.2$ vs. $0.3+0.6$, respectively; $\mathrm{P}<0.0001]$.

To assess the ability of $\triangle \mathrm{CVP}$ to predict the NEinduced decrease in $\mathrm{CO}$, the area under the curve (AUC) analysis was used, and the result was 0.859 with $95 \% \mathrm{CI}$ : 0.743-0.975 (Figure 4). A cutoff of $\triangle \mathrm{CVP}>1.5 \mathrm{mmHg}$ for detecting decreased $\mathrm{CO}$ resulted in a sensitivity of $75 \%$ and a specificity of $94.1 \%$. Using $\triangle \mathrm{CVP}$ to predict an NEinduced amplification of $\mathrm{Eh}$, the AUC was 0.938 with $95 \%$ CI: $0.881-0.995$ (Figure 4). A cutoff of $\Delta \mathrm{CVP}>1.5 \mathrm{mmHg}$ 

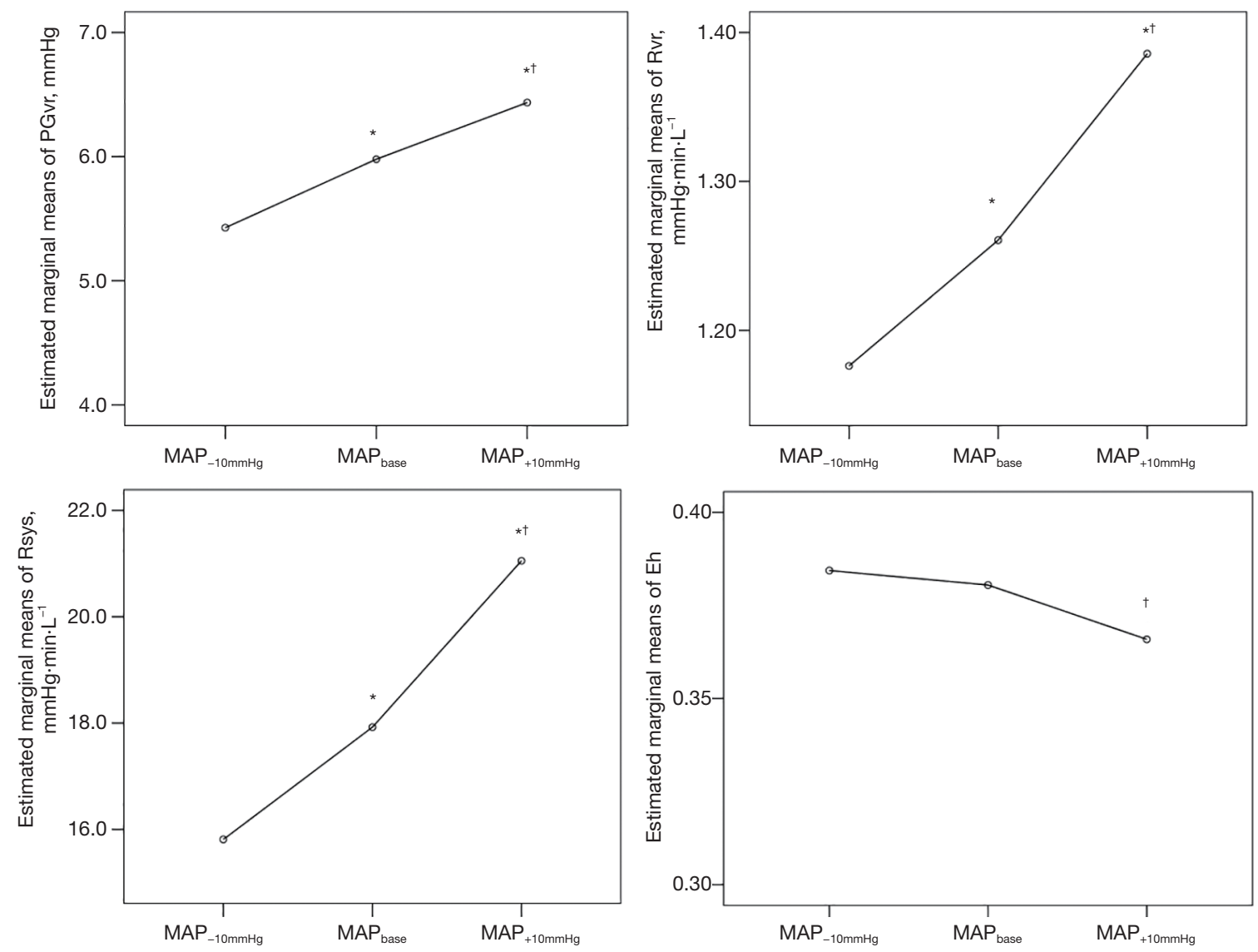

Figure 2 Estimated marginal means of $\mathrm{PGvr}$, Rvr, Rsys and Eh in 27 patients at three MAP levels. ${ }^{*}, \mathrm{P}<0.05$ vs. MAP ${ }_{-10 \mathrm{mmHg}}{ }^{\dagger}, \mathrm{P}<0.05$ vs. $\mathrm{MAP}_{\text {base }}$ PGvr, pressure gradient for venous return; Rvr, resistance of venous return; Rsys, resistance of systemic vasculature; Eh, efficiency of heart; MAP, mean arterial pressure ( $\mathrm{mmHg}$ ).

for detecting decreased Eh resulted in a sensitivity of $64.3 \%$ and a specificity of $100 \%$.

\section{Discussion}

The present study showed that (I) a stepwise increase in NE infusion dose produced a significant and continuously increasing trend in the driving pressure of venous return, Rvr and systemic circulation. (II) There were highly divergent responses in $\mathrm{Eh}$ and $\mathrm{CO}$ to $\mathrm{NE}$ challenge episodes following an NE-induced $10 \mathrm{mmHg}$ increase in MAP. (III). An increase in CVP may be an early alarm to identify the reduction in $\mathrm{CO} / \mathrm{Eh}$ during the NE-induced increase in MAP.

\section{Effect of increasing NE on venous return}

Pmsf is the precise physiologically variable that is used to assess the systemic volume state, and the venous return is determined as the pressure gradient between Pmsf and $\operatorname{RAP}(15,16)$, which is defined as the pressure in the vascular system during circulatory arrest (17). The Pmsf has attracted increasing interest in critically ill patients, and it was used to interpret the effect of NE on venous return $(3,4)$.

The present study used a mathematical model to calculate the mean systemic pressure (Pmsa) and derived variables to assess the effect of increasing $\mathrm{NE}$ on venous return. Increases in venous and systemic resistance $(\Delta \mathrm{Rvr}$ and $\Delta$ Rsys) were related to a decrease in $\mathrm{CO}$, and the increase in driving pressure venous return was related to an NEinduced increase in $\mathrm{CO}$ in the present study. An increase in the NE infusion rate induced a continuous increase in the driving pressure of venous return and the resistance of venous and system. Werner-Moller et al. found that Pmsa was a good surrogate for standard Pmsf measured at zero blood flow (6). Our study also supported the feasibility of 

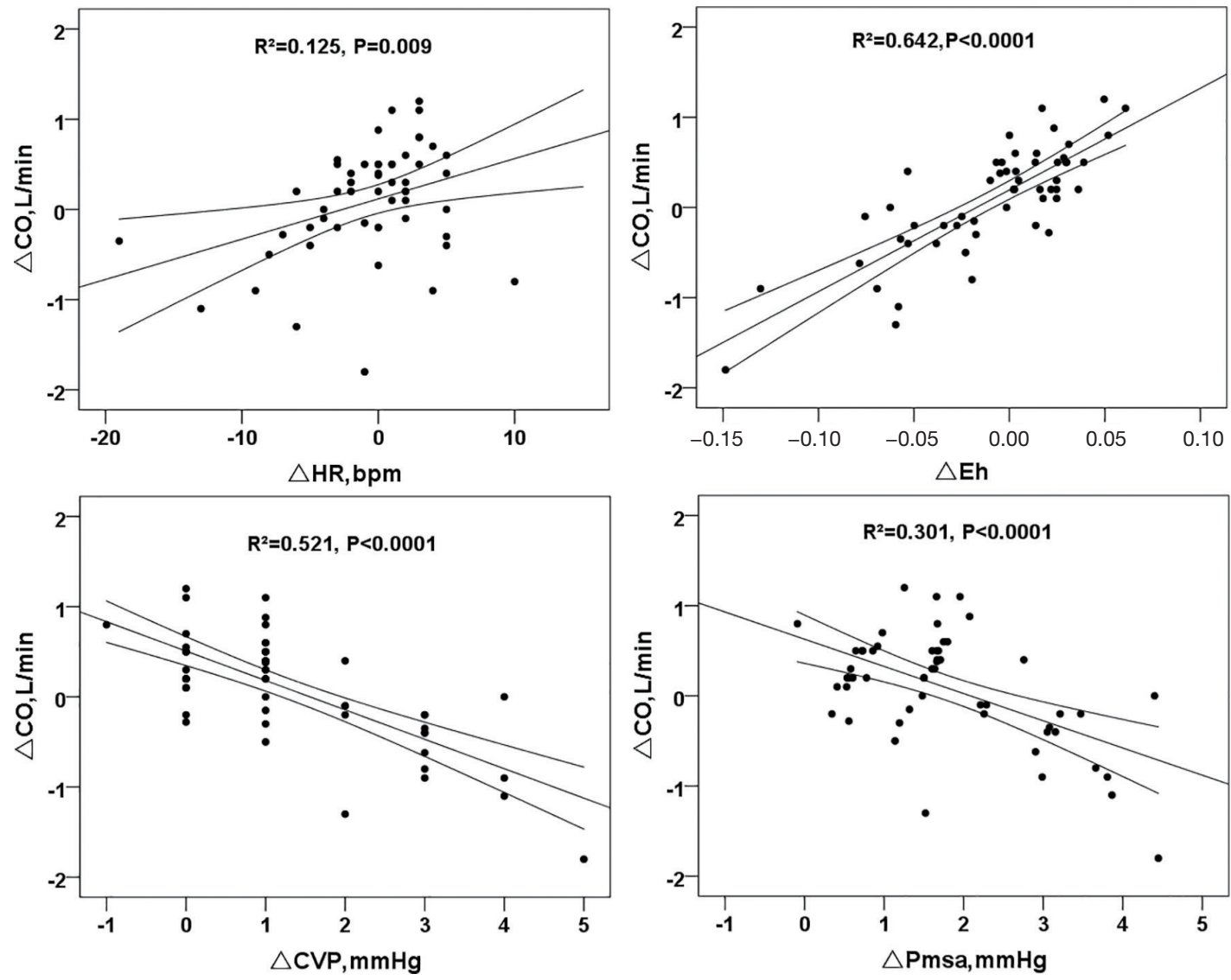

Figure 3 Linear regression analysis of the relationship between the $\Delta$ cardiac output (CO), the $\Delta$ heart rate (HR), the $\Delta$ central venous pressure (CVP) and the $\Delta$ Pmsa in the 54 NE challenges. Pmsa, mean systemic pressure of model analog; Eh, efficiency of heart.

Pmsa to assess the effect of $\mathrm{NE}$ on venous return in clinical practice. A formal experimental demonstrated that CVP, as backpressure to venous return, inversely correlated to CO (18). A consistent result was found in the present study.

\section{Changes in $\mathrm{CO}$ and $\mathrm{Eb}$ in the $\mathrm{NE}$ challenges}

The present study used the venous return curve and cardiac function curve to interpret cardiovascular responses based on Guyton's theory. A schematic diagram of the effects of $\mathrm{NE}$ on $\mathrm{CO}$ is shown in Figure 5. The CO responses to NE are divided into three conditions. (I) CO-increasing and Eh-amplifying responses to NE (Figure 5A): NE shifted the venous return curve to the right (and increased Pmsa and Rvr) without affecting the cardiac function curve at a steep stage. As a result, $\mathrm{NE}$ caused an increase in $\mathrm{CO}$ with a smaller change in CVP. A slight change in CVP and a greater increase in $\mathrm{CO}$ indicated $\mathrm{Eh}$ amplification. Two studies reported that the early administration of an $\mathrm{NE}$ infusion or an increased infusion rate recruited unstressed volume to stressed volume and increased the cardiac preload (defined as left ventricular end-diastolic area) and $\mathrm{CO}$ in septic shock patients $(19,20)$. (II) CO-little changed an Eh-reducing response to NE (Figure 5B): NE shifted the venous return curve to the right (and increased Pmsa and Rvr) without affecting the cardiac function curve, which was at a relatively flat stage. As a result, NE caused an increase in CO-unchanged with an increase in CVP. an increase in CVP and a slight change in CO demonstrated that NE reduced Eh. Several studies found that NE infusion was associated with an unchanged $\mathrm{CO}$ in cardiogenic shock $(21,22)$, head trauma, and septic patients (23). (III) COdecreasing and Eh-reducing responses to NE (Figure 5C): NE shifted the venous return curve to the right (and increased Pmsa with a greater increase in Rvr) and shifted the cardiac function curve to the left (i.e., the ability of heart ejection may be impaired with an NE-induced increase of afterload, and the increase of afterload was always inversely 

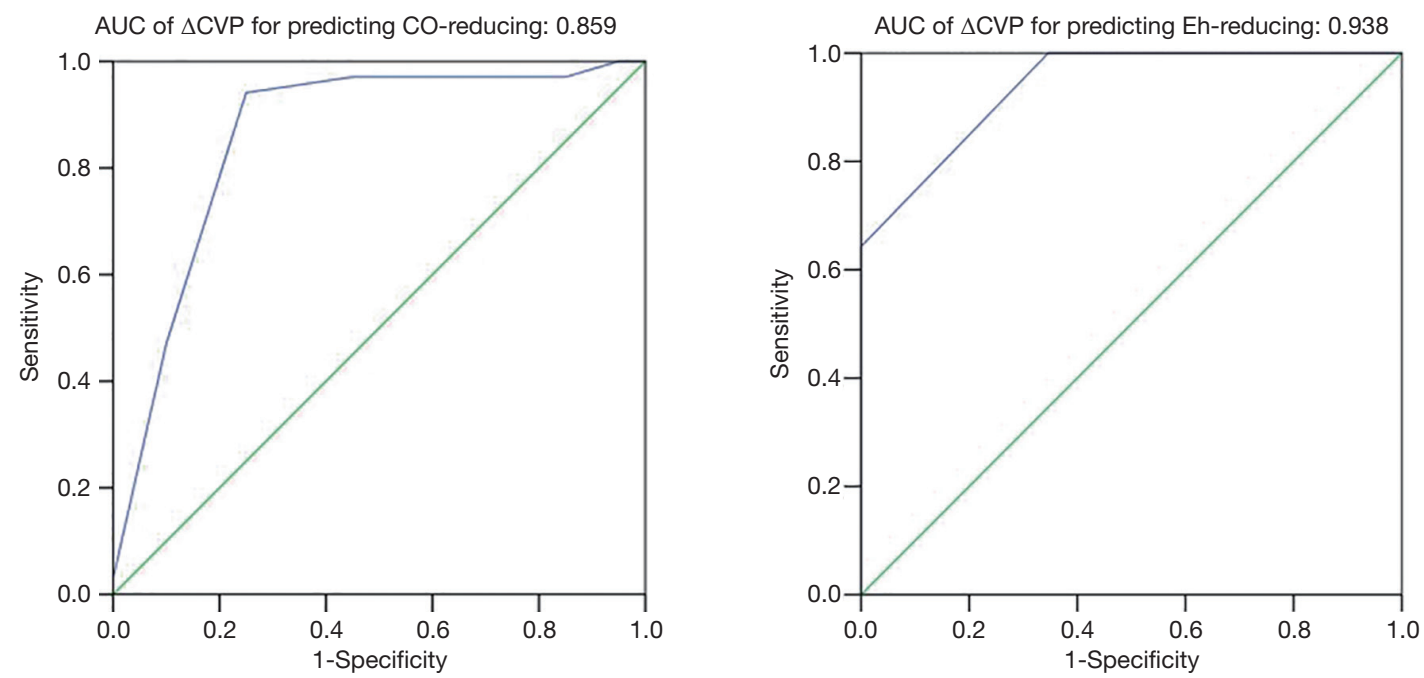

Figure 4 ROC curves using $\triangle \mathrm{CVP}$ to predict CO-reducing and Eh-reducing responses to the increased NE. ROC, receiver operating characteristic; CVP, central venous pressure; CO, cardiac output (L/min); NE, norepinephrine ( $\mu \mathrm{g} / \mathrm{kg} / \mathrm{min})$; Eh, efficiency of heart; AUC, area under the curve.
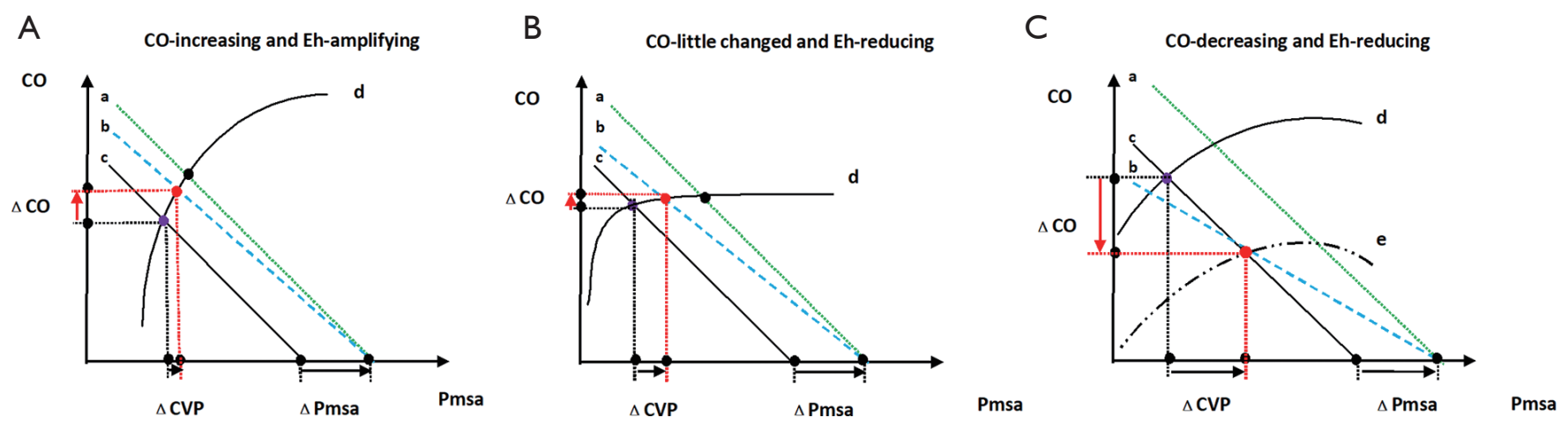

Figure 5 Three types for cardiac output (CO) directional changes to a norepinephrine (NE) challenge based on the venous return curve and cardiac function curve. (A) "CO-increasing and efficiency of heart (Eh)-amplifying" response to NE; (B) "CO-little changed and Ehreducing" response to NE; (C) "CO-decreasing and Eh-reducing" response to NE. The venous return (VR) curve and CO curve were constructed from central venous pressure (CVP), an analog model of mean systemic pressure (Pmsa), and CO. Line "a" indicates the baseline VR curve; line " $\mathrm{b}$ " indicates the volume effect of NE-induced generalized venoconstriction on CO; line "c" indicates the additional effect of venoconstriction on resistance to venous return (Rvr); line " $\mathrm{d}$ " indicates the baseline cardiac function curve; line "e" indicates the NE-induced impairment of cardiac function curve.

correlated to $\mathrm{CO})$. As a result, $\mathrm{NE}$ caused a decrease in $\mathrm{CO}$ with an increase in CVP. Desjars et al. observed that NEinduced increased MAP produced a drop in $\mathrm{CO}$ in septic patients (24). Conversely, López et al. found that the use of nitric oxide synthase inhibition to increase MAP induced a decrease in CO in hypotensive septic shock patients (25). A recent animal study found that an increase of $\mathrm{NE}$ and volume expansion increased ECMO (7). NE increased vascular resistance and pump afterload, but volume expansion caused a decrease of vascular resistance and pump afterload (7). The CVP-increasing response combined with the COdecreasing response demonstrated that NE impaired Eh.

In summary, all three of the above-mentioned CO responses to $\mathrm{NE}$ were reported in previous clinical studies. The role of HR should also be considered in the interpretation of the directional change of $\mathrm{CO}$. An increase 
in NE may directly stimulate $\beta$-adrenergic receptors and further amplify CO. the increase in HR correlated with an increase in the NE challenge-induced $\mathrm{CO}$ response in the present study. A previous study also found that HR decreased in patients with a CO-decreasing response (3).

\section{Clinical relevance of the $N E$ challenge}

Guarracino et al. reported that the assessment of cardiovascular response using the mathematical model used in this study was highly heterogeneous during guidelinebased resuscitation in septic shock patients (26). We found that an increase in CVP may be an early alarm for the reduction in $\mathrm{CO}$ and Eh following the administration of NE. Therefore, the dynamic monitoring of changes in CVP may provide useful information for the identification of impaired cardiac function caused by increasing NE. The cutoff value of $\triangle \mathrm{CVP}$ related to NE-induced impaired cardiac function was, to our knowledge, determined for the first time in septic shock patients in the present study. The present study showed that an elevation of CVP $>1.5 \mathrm{mmHg}$ was related to the reductions in $\mathrm{CO}$ and Eh during the increased NE.

The $\mathrm{CO}$ was not equal to the Eh. Eh reflects the efficiency of the heart as a global measure and was calculated by changes in CVP, CO and MAP. The present study showed that $\triangle \mathrm{CO}$ was significantly related to $\Delta \mathrm{Eh}$. However, some patients had a small increase in $\mathrm{CO}$ with a reduction in $\mathrm{Eh}$ in response to $\mathrm{NE}$. We emphasize that the change in Eh may provide further useful information to optimize cardiac function during the use of NE to maintain MAP in septic shock patients.

\section{Limitations}

First, the present study should be regarded as a physiological study because all of the patients were in a stable condition without hypotension. The initial $\mathrm{MAP}_{\text {base }}$ was optimized based on local hemodynamic therapy principle. Our main finding is that an increase of $\triangle \mathrm{CVP}$ following $\mathrm{NE}$ titration indicates the presence of an NE-induced impaired cardiac function. Therefore, $\triangle \mathrm{CVP}$ following NE may be an alarm indicator for the identification of NE-induced heart impairment. Second, we arbitrarily choose an NE-induced increase of $10 \mathrm{mmHg} \mathrm{MAP}$ as an NE challenge to the heart. For medical safety, the adjustment of MAP was required to be mild. Notably, an NE-induced $10-\mathrm{mmHg}$ change in MAP caused a variety of changes in $\mathrm{CO}$ and Eh. Maas et al. found that $\mathrm{NE}$-induced $20-\mathrm{mmHg}$ increases in arterial pressure were associated with an increase or decrease in $\mathrm{CO}$ in stable postoperative cardiac surgery patients (3). Third, mathematical coupling may exist between the related parameters (CVP, MAP, CO and Pmsa) because Pmsa was derived from a calculated formula in our study. Recent clinical studies showed that volume-induced changes in Pmsf were reliably tracked by changes in Pmsa, and the Pmsa and Pmsa-derived variables provided an assessment of the efficiency of volume expansion in postsurgical cardiac patients (27-30). An animal study showed that Pmsa had a good ability to assess the standard Pmsf (6). Pmsa may be a promising indicator in bedside hemodynamic monitoring. Fourth, because two NE challenges were included for each patient, the individual patient information at baseline is not appropriate for analysis in the NE challenge test. Fifth, Eh is an indirect measure of the ability of the heart to maintain the stressed volume. It may be more interesting and relevant to relate Eh to the stress volume in the present study. Some clinical studies showed that the stressed volume could be calculated during fluid challenge. Mass et al. calculated the stress volume using Pmsf (using the inspiratory hold method) and systemic compliance at the difference volume status (3). Pmsf was measured before and after fluid administration. Stressed volume was determined by extrapolating the Pmsf-volume curve to the zero-pressure intercept. Moreover, the systemic compliance was assumed to be unchanged (31). However, the related condition was different in our study. A known value of volume change was lacking in the present study, and the systemic compliance always was variable during the NE change. Further study is required to investigate the effect of $\mathrm{NE}$ on the stress volume.

\section{Conclusions}

Divergent responses in $\mathrm{CO}$ and Eh to $\mathrm{NE}$ challenge were interpreted via the application of a mathematical model for the calculation of mean systemic pressure. An increase in CVP may be an early alarm to identify the reduction in CO /Eh during the NE-induced increase of MAP.

\section{Acknowledgments}

Funding: This work was supported by the Beijing Natural Science Foundation (No. 7202157), Chinese Academy of Medical Sciences (CAMS) Innovation Fund for Medical Sciences (CIFMS) from Chinese Academy of Medical 
Sciences (grant number 2020-I2M-2-005), and the National Key Research and Development Program of China (grant number 2020YFC0841300). 2018 Beijing Dongcheng District Excellent Talents Training Funding Project.

\section{Footnote}

Reporting Checklist: The authors have completed the STARD reporting checklist. Available at http://dx.doi.org/10.21037/ atm-20-6686

Data Sharing Statement: Available at http://dx.doi. org/10.21037/atm-20-6686

Conflicts of Interest: All authors have completed the ICMJE uniform disclosure form (available at http://dx.doi. org/10.21037/atm-20-6686). The authors have no conflicts of interest to declare.

Etbical Statement: The authors are accountable for all aspects of the work in ensuring that questions related to the accuracy or integrity of any part of the work are appropriately investigated and resolved. The investigation was performed according to the principles outlined in the Declaration of Helsinki (as revised in 2013). The institutional review board of Peking Union Medical College Hospital approved the study protocol (No. ZS910, approved at 2015). Written informed consent was obtained from all patients or next of kin before the data were included in the study.

Open Access Statement: This is an Open Access article distributed in accordance with the Creative Commons Attribution-NonCommercial-NoDerivs 4.0 International License (CC BY-NC-ND 4.0), which permits the noncommercial replication and distribution of the article with the strict proviso that no changes or edits are made and the original work is properly cited (including links to both the formal publication through the relevant DOI and the license). See: https://creativecommons.org/licenses/by-nc-nd/4.0/.

\section{References}

1. He H, Long Y, Zhou X, et al. Oxygen-Flow-Pressure Targets for Resuscitation in Critical Hemodynamic Therapy. Shock 2018;49:15-23.

2. Foulon P, De Backer D. The hemodynamic effects of norepinephrine: far more than an increase in blood pressure! Ann Transl Med 2018;6:S25.

3. Maas JJ, Pinsky MR, de Wilde RB, et al. Cardiac output response to norepinephrine in postoperative cardiac surgery patients: interpretation with venous return and cardiac function curves. Crit Care Med 2013;41:143-50.

4. Persichini R, Silva S, Teboul JL, et al. Effects of norepinephrine on mean systemic pressure and venous return in human septic shock. Crit Care Med 2012;40:3146-53.

5. Parkin WG, Leaning MS. Therapeutic control of the circulation. J Clin Monit Comput 2008;22:391-400.

6. Werner-Moller P, Sondergaard S, Jakob SM, et al. Effect of volume status on the estimation of mean systemic filling pressure. J Appl Physiol (1985) 2019;126:1503-13.

7. Moller PW, Hana A, Heinisch PP, et al. The Effects of Vasoconstriction And Volume Expansion on Veno-Arterial ECMO Flow. Shock 2019;51:650-8.

8. He HW, Liu W L, Zhou X, et al. Effect of mean arterial pressure change by norepinephrine on peripheral perfusion index in septic shock patients after early resuscitation. Chin Med J (Engl) 2020;133:2146-52.

9. Levy MM, Fink MP, Marshall JC, et al. 2001 SCCM/ ESICM/ACCP/ATS/SIS International Sepsis Definitions Conference. Crit Care Med 2003;31:1250-6.

10. Knaus WA, Draper EA, Wagner DP, et al. APACHE II: a severity of disease classification system. Crit Care Med 1985;13:818-29.

11. Berger D, Moller PW, Takala J. Reply to "Letter to the editor: Why persist in the fallacy that mean systemic pressure drives venous return?". Am J Physiol Heart Circ Physiol 2016;311:H1336-7.

12. Berger D, Moller PW, Weber A, et al. Effect of PEEP, blood volume, and inspiratory hold maneuvers on venous return. Am J Physiol Heart Circ Physiol 2016;311:H794-806.

13. Roy A. Estimating correlation coefficient between two variables with repeated observations using mixed effects model. Biom J 2006;48:286-301.

14. McCulloch CE, and Searle SR. Generalized, Linear, and Mixed Models. John Wiley and Sons, 2000.

15. Magder S. Point: the classical Guyton view that mean systemic pressure, right atrial pressure, and venous resistance govern venous return is/is not correct. J Appl Physiol (1985) 2006;101:1523-5.

16. Guyton AC. Determination of cardiac output by equating venous return curves with cardiac response curves. Physiol Rev 1955;35:123-9.

17. Jansen JR, Maas JJ, Pinsky MR. Bedside assessment of mean systemic filling pressure. Curr Opin Crit Care 
2010;16:231-6.

18. Moller PW, Winkler B, Hurni S, et al. Right atrial pressure and venous return during cardiopulmonary bypass. Am J Physiol Heart Circ Physiol 2017;313:H408-20.

19. Hamzaoui O, Georger JF, Monnet X, et al. Early administration of norepinephrine increases cardiac preload and cardiac output in septic patients with life-threatening hypotension. Crit Care 2010;14:R142.

20. Monnet X, Jabot J, Maizel J, et al. Norepinephrine increases cardiac preload and reduces preload dependency assessed by passive leg raising in septic shock patients. Crit Care Med 2011;39:689-94.

21. Rokyta R Jr, Tesarová J, Pechman V, et al. The effects of short-term norepinephrine up-titration on hemodynamics in cardiogenic shock. Physiol Res 2010;59:373-8.

22. Albanèse J, Leone $M$, Garnier F, et al. Renal effects of norepinephrine in septic and nonseptic patients. Chest 2004;126:534-9.

23. Martin C, Papazian L, Perrin G, et al. Norepinephrine or dopamine for the treatment of hyperdynamic septic shock? Chest 1993;103:1826-31.

24. Desjars P, Pinaud M, Potel G, et al. A reappraisal of norepinephrine therapy in human septic shock. Crit Care Med 1987;15:134-7.

25. López A, Lorente JA, Steingrub J, et al. Multiple-center, randomized, placebo-controlled, double-blind study of the

Cite this article as: He H, Yuan S, Long Y, Liu D, Zhou X, Ince C. Effect of norepinephrine challenge on cardiovascular determinants assessed using a mathematical model in septic shock: a physiological study. Ann Transl Med 2021;9(7):561. doi: 10.21037/atm-20-6686 nitric oxide synthase inhibitor 546C88: Effect on survival in patients with septic shock. Crit Care Med 2004;32:21-30.

26. Guarracino F, Bertini P, Pinsky MR. Cardiovascular determinants of resuscitation from sepsis and septic shock. Crit Care 2019;23:118.

27. Maas JJ, Pinsky MR, Geerts BF, et al. Estimation of mean systemic filling pressure in postoperative cardiac surgery patients with three methods. Intensive Care Med 2012;38:1452-60.

28. Cecconi M, Aya HD, Geisen M, et al. Changes in the mean systemic filling pressure during a fluid challenge in postsurgical intensive care patients. Intensive Care Med 2013;39:1299-305.

29. Gupta K, Sondergaard S, Parkin G, et al. Applying mean systemic filling pressure to assess the response to fluid boluses in cardiac post-surgical patients. Intensive Care Med 2015,41:265-72.

30. Maas JJ, Geerts BF, Jansen JR. Evaluation of mean systemic filling pressure from pulse contour cardiac output and central venous pressure. J Clin Monit Comput 2011;25:193-201.

31. Maas JJ, Pinsky MR, Aarts LP, et al. Bedside assessment of total systemic vascular compliance, stressed volume, and cardiac function curves in intensive care unit patients. Anesth Analg 2012;115:880-7. 